International Journal of Current Advanced Research

ISSN: O: 2319-6475, ISSN: P: 2319 - 6505, Impact Factor: SJIF: 5.995

Available Online at www.journalijcar.org

Volume 6; Issue 4; April 2017; Page No. 3153-3155

DOI: http://dx.doi.org/10.24327/ijcar.2017.3155.0208

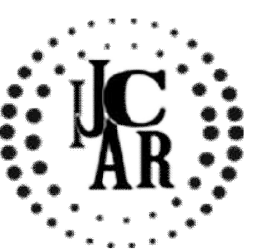

Review Article

\title{
AWARENESS OF DOSAGE AND COMPLICATIONS OF LOCAL ANAESTHESIA AMONG DENTAL PRACTITIONERS- A SURVEY
}

\author{
Amurdhavani and Nabeel Nazar
}

Saveetha Dental College and Hospital, Chennai

\section{A R R T I C L L E $\quad$ I N F F O \\ Article History: \\ Received $15^{\text {th }}$ January, 2017 \\ Received in revised form $16^{\text {th }}$ February, 2017 \\ Accepted $22^{\text {nd }}$ March, 2017 \\ Published online $28^{\text {th }}$ April, 2017}

\section{Key words:}

Complications Of Local Anaesthesia, Dental Practitioners

\begin{abstract}
A B S T R A C T
Aim: The present study was undertaken to assess the knowledge of dosage and complications of local anaesthesia among undergraduates and postgraduates.

Objective: The aim of this study was to determine the knowledge that dental practitioners have regarding dose calculations, the maximum dose required of the most commonly used local anesthetics and other complications. A survey questionnaire was used in this study and data were analysed from 100 dental students.

Background: Local anesthetics are the most commonly used drugs in dentistry. Although they are considered effective and safe in controlling pain during dental procedures, complications related to their use appear inevitable. Many dentists use these drugs routinely but are unaware of the dose calculations required and the maximum safe and effective dose of the drug.

Reason: This study is conducted to assess the awareness of dosage because lack of awareness of the correct dose calculation is obviously worrying and a number of complications can arise from the incorrect administration of local anesthetic injections.
\end{abstract}

Copyright $\odot 2017$ Amurdhavani and Nabeel Nazar. This is an open access article distributed under the Creative Commons Attribution License, which permits unrestricted use, distribution, and reproduction in any medium, provided the original work is properly cited.

\section{INTRODUCTION}

Local anesthetics are frequently administered indentistry and thus can be expected to be a major sourceofdrug-related complicationsin the dental office. Additionally, duetoincreasing life expectancies as well as progress in medical and dental therapeutic treatments, today's dentistswillmoreoftenhaveto treatrisk patients; therefore, the incidence of systemic complicationscan be expected to rise.The use of such drugs aims to inhibit nerve conduction during a variety of dental procedures [1]. These drugs are classified as ester or amide type with short, intermediate or long acting action. In addition to the local anesthetic agent in the local anesthetic cartridge other constituents, such as vasoconstrictors are of great importance during the administration of local anesthetic [2]. During their routine work most dentists who use such drugs often ignore important aspects of drug administration, notably the maximum dose and the dose calculation which relate to the use of local anesthetics. Most dentists memorise the maximum number of cartridges and the total contents in milligrams of local anesthetic per cartridges [3]. The required dose of local anesthetic is based on many factors including age and weight, and medically compromised patients and children require special consideration when calculating the maximum dose of a local anesthetic or a vasoconstrictor [4].

*Corresponding author: Amurdhavani

Saveetha Dental College and Hospital, Chennai
Failure of anesthesia leads to more local anesthetic being administered in order to achieve the required effect, and toxic reactions to local anesthetics can occur when the local concentration of the drug in the blood stream becomes elevated over a short time period. High concentrations of the drug in the circulation may result from an inadvertent, rapid injection directly into a blood vessel, or to the use of repeated injections, and there is always a risk of intravenous administration when injections are made into a highly vascular area [5]. Although toxic reactions are more commonly encountered during the use of nerve block techniques than infiltrations, some authors recommend performing two negative aspirations even when infiltration technique is used. Dentists should be fully awareofthedoserequiredand the dosecalculations used for local anesthetics and should perform aspiration in all injections in order to avoid sudden intravascular injections which lead to drug toxicity. The aim of this study was to investigate the awareness andknowledge of general dental practitioners and specialists regarding the maximum dose of the commonly used local anesthetic drug lidocaine. The study also determined (a) the most commonly used local anesthetic drugs by dentists, (b) the most frequently encountered complications during, or after, local anesthetic administration and (c) whether or not aspiration is a common practice usedbydentistal practitioners 


\section{MATERIALS AND METHODS}

A total of 100 questionnaires were designed, and used, to investigate the awareness of general dental practitioners regarding the maximum dose of the most commonly used local anaesthetic, lidocaine. The questionnaire included questions relating to age, gender, and qualification, and investigated the practitioner's awareness of the maximum dose of $2 \%$ lidocaine with adrenaline for adult healthy patients in terms of dose per kilogram, and the name of the most commonly used anaesthetic drug used in the correspondents' clinic. The questionnaire also questioned awareness of the meaning of a $2 \%$ concentration in local anaesthetic dose calculation. The questionnaire asked whether or not the dentist performs aspiration in different injection techniques and questioned the types of complications that the dentist had encountered during, or after, the administration of a local anesthesia.

\section{RESULTS}

A high percentage of the dentists (82\%) were aware of calculating methods for the local anesthetic dose (Figure 1).

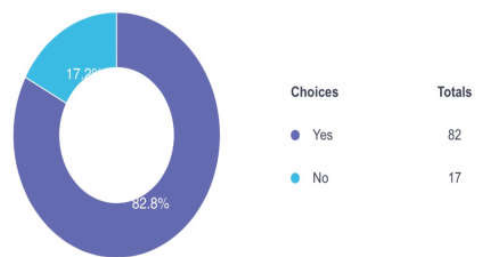

Fig. 1 Number of dental practitioners who are aware of dosage calculations of LA

The most commonly used anaesthetic drug used by dental practitioners is lignocaine (Figure 2).

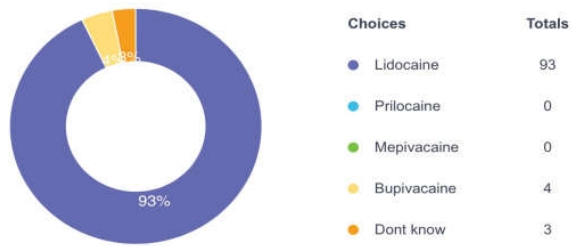

Fig 2 Most commonly used anaesthetic in Clinics

Only 33\%of all respondents gave the correct answer to the question regarding the maximum dose of $2 \%$ lidocaine with vasoconstrictor (Figure 3).
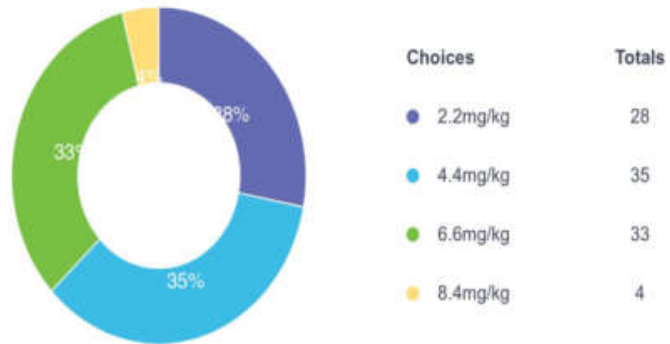

Fig. 3 The maximum dose in $\mathrm{mg}$ for $2 \%$ lidocaine with vasoconstrictor $88 \%$ of dental practitioners prefer local anaesthesia with adrenaline.
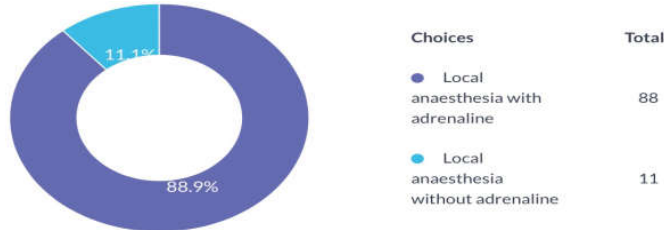

Fig. 4 What the dental practitioners prefer?
$67 \%$ of dental practitioners are aware about the various complications of LA
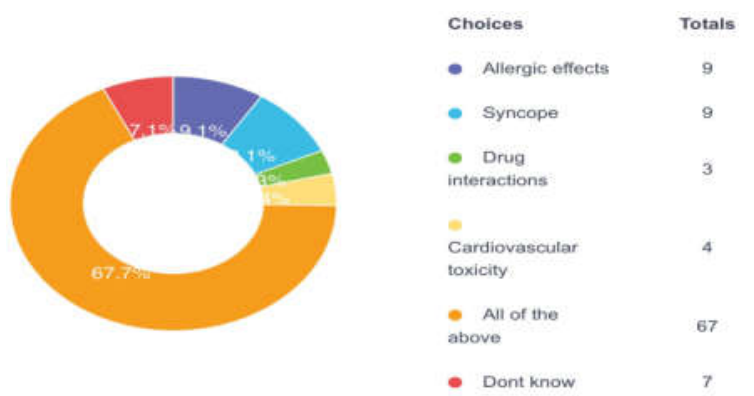

Fig. 5 Complications of local anaesthesia

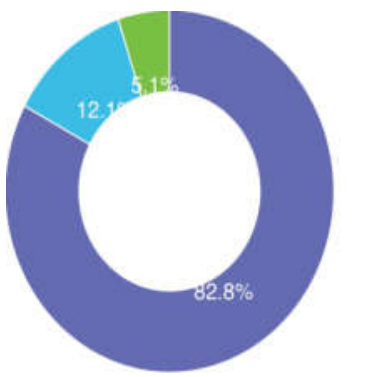

Choices
$\begin{aligned} & \text { In all injections } \\ & \text { Only during }\end{aligned}$
$\begin{aligned} & \text { inferior alveolar } \\ & \text { nerve block }\end{aligned}$
$\begin{aligned} & \text { During some } \\ & \text { other specific } \\ & \text { nerve block }\end{aligned}$

Fig 6 When is the aspiration done?

$82 \%$ of dental practitioners aspirate in all injections $68 \%$ of dental practitioners are aware of most important complication of local anesthesia with epinephrine $58 \%$ of dental practitioners are aware that patient's weight is most important to calculate maximum safe dose of LA

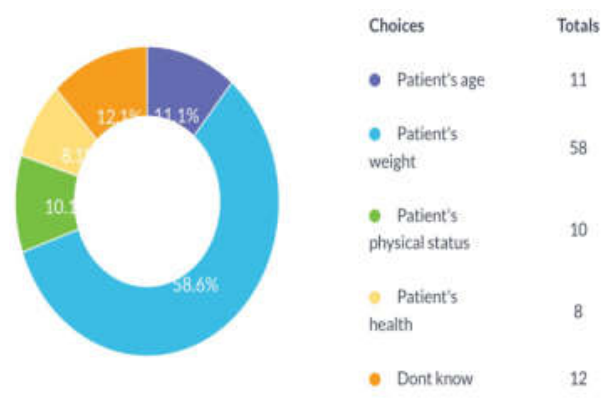

Fig 7 complication of local anaesthesia with epinephrine

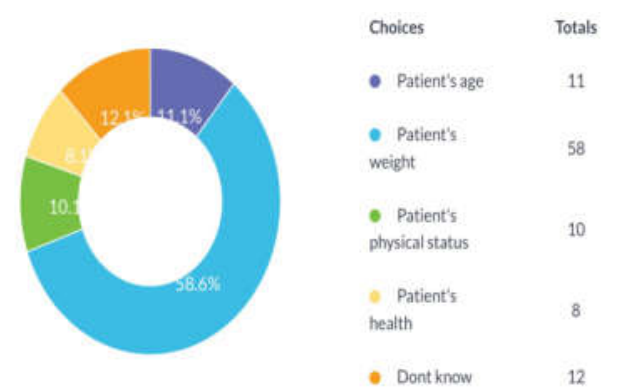

Fig. 8 On what basis the maximum safe dose of LA is calculated

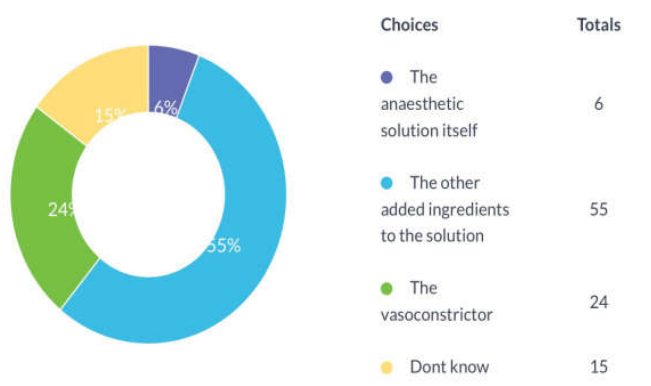

Fig. 9 The most common reason for allergies to local anesthesia solutions 
$55 \%$ of dental practitioners are are aware of the most common reason for allergies to local anesthesia solutions

\section{DISCUSSION}

A high percentage of the responding dentists (82\%) were clear that there are calculating methods for the local anesthetic dose (Figure 1). The most commonly used anaesthetic drug used by dental practitioners is lignocaine(Figure 2). Only $33 \%$ of all respondents gave the correct answer to the question regarding the maximum dose of $2 \%$ lidocaine with vasoconstrictor (Figure 3). This survey showed no significant difference between general dental practitioners and specialists in relation to the correct answer. $88 \%$ of dental practitioners prefer local anaesthesia with adrenaline. Local anesthesia (LA) with epinephrine have an important role in pain and bleeding control. A number of complications can arise from the incorrect administration of local anesthetic injections, some of which are permanent and can damage patients or even be life threatening [6-10].

$99 \%$ of them are aware of complications of higher doses of local anaesthesia with epinephrine and $67 \%$ of them are aware of systemic complications of local anesthesia (Figure 4).Syncope may be related to the fear of the dental injection and anxiety related events. Failure of local anesthetics to be effective is related to many factors such as, inaccurate anatomical deposition of the local anesthetic solution or the use of inadequate amounts of solution. $68 \%$ of dental practitioners were aware of contraindications of local anaesthesia with epinephrine However, most clinicians believe LA + epinephrine may cause rapid raise in blood pressure (BP) and heart rate (HR). Addition of adrenaline to local anaesthetic solution is contraindicated for the following diseases like heart diseases, untreated or uncontrolled severe hypertension, uncontrolled hyperthyroidism, uncontrolled diabetes etc. Dosage calculation is based on patient's weight and only $58 \%$ of them were aware of it.The results also show that $99 \%$ of general dental practitioners perform aspiration when injecting local anesthetics, while only $1 \%$ perform do not aspirate. A question was asked regarding when do they aspirate $.82 \%$ of dental practitioners aspirate in all injections, $12 \%$ aspirate during inferior alveolar nerve block and 5\% aspirate during other nerve blocks(Figure 5). When injecting into a blood vessel (for example during intravenous sedation) it is essential to aspirate blood into the syringe prior to drug administration to ensure that the tip of the needle is lying within a vein. By the same token, when the injection is intended to be extravascular it would appear to be wise to ensure that no blood is aspirated into the syringe before drug delivery. 55\% of dental practitioners believe that allergic reactions are due to added ingredients in local anaesthetic solutions. Allergic reactions have been shown to becaused by co-incidental exposure to other antigens such as preservatives (e.g., methyl - p -hydroxybenzoate), antioxidants (e.g., bisulphate), antiseptics (e.g., chlorhexidine), and other antigens such as latex, as well as local anesthetic drugs [1113].The determination of local anesthetist dosage, dose calculations and awareness of complications remains a problem for most of the dentists sampled here. The inability to understand and manipulate such important issues in dentistry is of considerable concern as it is likely to render dentists unsafe health providers.

\section{CONCLUSION}

In conclusion, the knowledge of dental practitioners concerning the local anaesthetics maximum-dose and dose calculations appears inadequate and worrying, especially since systemic toxicity of local anaesthetics is dose dependent. It is recommended that further educational courses are provided in order to update dental practitioners regarding the correct application of these critically important aspects in dentistry.

\section{References}

1. Ayoub ST, Coleman AE. A review of local anesthetics. Gen. Dent. 1992; 40(4):285-90.

2. Wahl MJ, Brown RS. Dentistry's wonder drugs: local anesthetics and vasoconstrictors. Gen. Dent. Mar. 2010; 58(2):114-23.

3. Becker DE, Reed KL. Local anesthetics: review of pharmacological considerations. Anesth. Prog. 2012; 59(2):90-101.

4. Nakai Y, Milgrom P, Mancl L, Coldwell SE, Domoto PK, Ramsay DS. Effectiveness of local anesthesia in pediatric dental practice. J. Am. Dent. Assoc. Dec. 2000; 131(12):1699-705.

5. Blanton PL, Jeske AH. Misconceptions involving dental local anesthesia. Part 1: Anatomy. Tex. Dent. J. 2002;119(4):296-304, 306.

6. Liau FL, Kok SH, Lee JJ, Kuo RC, Hwang CR, Yang $\mathrm{PJ}$, et al. Cardiovascular influence of dental anxiety during local anesthesia for tooth extraction. Oral Surg. Oral Med. Oral Pathol. Oral Radiol. Endod. 2008; 105(1):16-26.

7. Conrado VC, de AJ, de Angelis GA, de Andrade AC, Timerman MM, Andrade MM, et al. Cardiovascular effects of local anesthesia with vasoconstrictor during dental extraction in coronary patients. Arq. Bras. Cardiol. 2007; 88(5):507-13.

8. Rishiraj B, Epstein JB, Fine D, Nabi S, Wade NK. Permanent vision loss in one eye following administration of local anesthesia for a dental extraction. Int. J. Oral Maxillofac. Surg. 2005; 34(2): 220-3.

9. Sapir S, Shapira Y, Amir E. Emergencies evolving from local anesthesia in the pediatric dental clinic: prevention and treatment. Refuat. Hapeh. Vehashinayim 2003; 20(4):28-34, 87.

10. Brown RS, Paluvoi S, Choksi S, Burgess CM, Reece ER. Evaluating a dental patient for local anesthesia allergy. Compend. Contin. Educ. Dent. 2002; 23(2):125-322, 134.

11. Wildsmith JA, Mason A, McKinnon RP, Rae SM. Alleged allergy to local anaesthetic drugs. Br Dent $J$. 1998; 184:507-10. [PubMed]

12. Kelly KJ, Walsh-Kelly CM. Latex allergy: a patient and health care system emergency. J EmergNurs. 1998; 24:539-45. [PubMed]

13. Schwartz HJ, Sher TH. Bisulfite sensitivity manifesting as allergy to local dental anesthesia. J Allergy Clin Immunol. 1985; 75:525-7. [PubMed] 